\title{
CHAGAS' DISEASE: PATHOLOGY OF CHRONIC
}

\section{LESIONS}

Zilton A. Andrade'

\section{ABSTRACT}

The morphologic features of the indeterminate and the chronic cardiac forms of Chagas' disease, and their clinical correlations, are briefly reviewed. The significance of mild focal myocarditis as the main change of the indeterminate form, the myocardial inflammation and fibrosis of the chronic cardiac form, plus the involvement of the conducting system, are particularly considered.

KEYWORDS: Chagas disease. Pathology. Indetermined form. Chronic cardiac form. Myocarditis. Fibrosis.

\section{INTRODUCTION}

The present work was written to comply with a request from "WHOTDR Scientific Working Group on Chagas' disease". This paper has been discussed by a small group of researchers as a "working paper", but has not been published in any form. As its contents seem of general interest for those interested on Chagas' disease research and practice, a decision was made to make the text accessible for them.

The majority of individuals with chronic Trypanosoma cruzi infection are asymptomatic. About 15 to $30 \%$ of them are expected to evolve toward the chronic progressive forms of the disease, after periods of time that may vary from 5 to 15 years or more. Thus, the pathology of chronic lesions of Chagas' disease will have to consider the following headings:

\section{Titular Researcher-Fiocruz.}

Address for letters: Laboratory of Experimental Pathology, Gonçalo Moniz Research Center Fiocruz - Rua Valdemar Falcão, 121, 40.295-001 Salvador, BA, Brasil.

E-mail: zilton@cpqgm.fiocruz.br 
A) Lesions of the chronic indeterminate form.

B) Lesions of the chronic progressive forms:

b.1)The cardiac form;

b.2)The digestive form.

\section{CHRONIC INDETERMINATE FORM OF CHAGAS' DISEASE}

\section{Definition}

Diagnosis is made in "asymptomatic individuals with parasitological and/or serological evidences of $T$. cruzi infection, exhibiting normal electrocardiogram and a normal digestive tract, as seen by contrasted radiography" (20). The literature contains several studies considering asymptomatic $T$. cruzi-infected individuals as belonging to the indeterminate form of Chagas' disease. This is misleading, since a patient with cardiac arrhythmias and even cardiomegaly, may still be asymptomatic. Although rarely, megaesophagus cases may occur in the absence of dysphagia, as megacolon may occur unassociated with constipation. The problem of sudden death due to Chagas' disease is illustrative on this regard. It has been tacitly assumed that sudden death may occur during the silent phase of $T$. cruzi infection. One post-mortem study made on 11 cases of sudden death, in presumed asymptomatic individuals, in whom positive serology for $T$. cruzi infection was secured from the post-mortem examination of pericardial fluid, revealed the classical picture of the chronic cardiac form of Chagas' disease (cardiomegaly, chronic passive congestion, and chronic diffuse myocarditis) in all of them (7).

Human studies

The pathology of this form of the disease was first described in individuals with positive serological test (s), dying of suicidal, accidental or sudden death (13). The gross appearance of the heart was said to be usually within normal limits or rarely slightly enlarged, due to concentric left ventricular hypertrophy. Sometimes, the description included the presence of focal dilatation at the apex of the left ventricle (apical aneurysm).

The hallmark of the indeterminate form of Chagas' disease is mild multifocal myocarditis. It appears as scattered small foci of interstitial infiltrations by lymphocytes, macrophages and plasma cells within the myocardium, sometimes disclosing a granulomatous structure (13). Changes can also involve the conducting tissue of the heart. Although serological diagnosis can be made by means of pericardial fluid, EKG tracings or X-ray pictures, they are usually not available, being a severe limitation for the correct diagnosis of the indeterminate form in those post-mortem cases. To 
obviate such problems, attempts have been made to study material taken during life, by means of endomyocardial biopsies. Although the obtaining of such material poses serious ethical problems, it has allowed for the application of more refined techniques, such as electron microscopy, histochemistry and immunohistochemistry. Obviously, studies with endomyocardial biopsies suffer from the problem of sampling errors, since the lesions are focally distributed. In one study, only $15 \%$ of the biopsies exhibited mild inflammatory changes, while $85 \%$ were histologically normal (18). In another study, $61 \%$ of the biopsies exhibited mild, nonspecific changes of myocyte degeneration, interstitial edema, inflammatory infiltrates and fibrosis (11). Studies about the correlation between myocardial biopsy findings and the clinical course of Chagas' disease have shown that the more severe the morphologic changes, the more likely was the patient to develop chronic cardiac sequelae $(11,15)$. The determination of the correct clinical stage of the disease during such studies has not always been attempted, although it is obviously of crucial importance..

In general, studies with human material tend to characterize the indeterminate form of the disease as a slowly evolving process, in which focal myocardial lesions gradually accumulate up to a point of provoking cardiac failure and death. Tarleton (25) has synthesized this point of view: "the earliest proposed and still the simplest explanation for chronic phase pathology is the cumulative damage due to parasite invasion of muscle cells, release of additional parasites, and a consequent inflammatory reaction which terminates in fibrosis".

To add to the confusion regarding the concept and significance of the indeterminate form, several investigators have demonstrated that serumpositive subjects, with normal ECG, may disclose functional cardiac disturbances when submitted to more refined and sensible tests, such as ergometry, 24-hour ECG, echocardiography, ventriculography, and so on $(17,19)$.

Experimental studies

The lack of an adequate experimental model has hampered the investigations on the indeterminate form of Chagas' s disease. Almost any mammal can be experimentally infected with $T$. cruzi. Although all of them would develop a more or less severe acute infection, some will soon die, others will evolve to self-cure, while some will remain chronically infected. However, unlike the situation in humans, none of them will progress toward a chronic cardiac form, with cardiomegaly, diffuse chronic myocarditis, arrhythmias and cardiac congestive failure, after a more or less prolonged period of silent infection. The dog is an exception (1). Recent ultrastructural studies in dogs have demonstrated that the inflammatory cells forming the 
picture of chronic focal myocarditis are represented by small and large lymphocytes, plasma cells, macrophages, and a few polymorphonuclears and mast cells. These cells are accumulated in focal areas of the interstitial tissue of the myocardium, and do not establish cell-to-cell contact with myocardiocytes, and do not invade or destroy them, as occurs during acute disease (2). Some focal lesions exhibit evidences of extracellular matrix degradation (dissolution, fragmentation, and thickening of both collagen and elastic fibers), associated with signs of apoptosis (nuclear condensation and fragmentation, formation of apoptotic bodies) of groups of inflammatory cells. Such changes were interpreted as indicative of a cyclic mechanism of evolution for the focal inflammatory lesions (5). As new lesions appear, the older ones are gradually removed by degradation of excess extracellular matrix (fibrolysis), and by resorption of the inflammatory exsudate (apoptosis), thus allowing prolonged asymptomatic host survival.

Transition to chronic cardiac form probably occurs through disappearance of or interference with, the immunological suppressive network. The inflammatory reaction of the chronic phase of Chagas' disease in humans has been recently characterized as consisting mainly of cytotoxic $\mathrm{CD}^{+}$- T lymphocytes (26). These cells were seen to express the Granzyme A cytotoxic factor (22). It has now been a consensus that $\mathrm{CD}^{+}$lymphocytes are the main $\mathrm{T}$-cell type responsible for immune activation in chronic Chagasic myocarditis (12). These cells are activated, through Class I MHC molecules, by macrophages containing remnants of $T$. cruzi. The absence of a $\mathrm{CD} 4^{+} \mathrm{T}$-cell response in the presence of $T$. cruzi antigens suggests that the presentation of these antigens through Class II MHC molecules is inhibited. However, other evidences suggest that the depletion of $\mathrm{CD}^{+}$lymphocytes during the chronic phase of Chagas' disease is related to selective apoptosis of these cells (14). In the mouse model of Chagas cardiomyopathy, stimulation of $\mathrm{T}$ cells results in apoptosis of $\mathrm{CD}^{+}$cells but not of $\mathrm{CD} 8^{+}$cells (21). Taken together, the morphologic and immunologic observations reviewed above support the concept that the indeterminate phase of Chagas' disease represents a state of host-parasite equilibrium rather than of progressive chronic myocardial damage.

\section{Clinical significance}

Functional significance of focal myocarditis was an important aspect to investigate with the canine model:. Dogs that recovered from acute phase disease and were apparently healthy after a couple of months were submitted to invasive and non-invasive functional cardiac exploration. Results regarding sinus-node recovering time, intracardiac conduction time under different degrees of induced tachycardia and atrial excitability levels, were measured before and after total pharmacological autonomic cardiac block. 
There were no differences when results were compared to those from normal non-infected control dogs, although moderate to mild focal myocarditis has been documented in all infected animals (24). Thus, focal myocarditis, of the type and degree seen in the indeterminate form of Chagas' disease, apparently is not sufficient to alter sensitive cardiac function tests. If this is so, how to explain the situation in humans with normal ECG, but showing alterations, which are revealed when more sensible tests were used? Three possibilities can be examined: 1) the emerging of early progressive cardiac form of the disease. Future studies, with clinical follow-up, might confirm this possibility; 2) presence of fibrous sequelae left within some strategic areas of the heart, following a particularly severe acute phase, as already documented with the canine model $(4) ; 3$ ) a sudden focal inflammatory lesion reaching a sensible tissue, such as the conduction system, appear as a reasonable explanation for transitory alterations of ECG, as observed in some patients.

\section{CHRONIC PROGRESSIVE CHAGAS' DISEASE}

The chronic cardiac form of Chagas' disease exemplifies an inflammatory cardiomyopathy which leads to arrhythmias, cardiomegaly, congestive cardiac failure and death. Death usually occurs within a few months to one year following the first clinical manifestations of congestive failure.

Endemic megacolon and megaesophagus are also associated with chronic $T$. cruzi infection and represent the chronic digestive form of Chagas' disease.

Several minor manifestations involving different organs can be observed in patients with chronic $T$. cruzi infection. They are of considerable academic interest and, sometimes, may assume practical importance. Disturbances can affect peristalsis and secretory function within the digestive tract, the secretion of endocrine and exocrine glands, the function of neuromuscular tissue and the central nervous system. Functional rather than morphological changes are usually reported. The main pathological changes have often been attributed to autonomic, peripheral and central nervous system damage. When these lesions are actually demonstrated they usually seem compatible with sequelae left by repair, probably from injury inflicted during the acute phase of the disease.

\section{CHRONIC CHAGAS' MYOCARDITIS}

Patients with Chronic Chagas' heart disease may die suddenly or more often after a variable course of congestive heart failure. Patients with congestive cardiac failure may die unexpectedly. Arrhythmias are a hallmark 
of chronic Chagas' heart disease. Lesions of the conducting system are prominent in almost every case, which is in keeping with the florid ECG findings typical of the disease.

Cardiomegaly, signs of chronic passive congestion and thromboembolic phenomena are the main gross pathological findings. Cardiomegaly is due to a combination of hypertrophy and dilatation. The weight of the heart varies from 380 to $760 \mathrm{~g}$ (average: $506 \mathrm{~g}$ ). Apical cardiac aneurysm occurs in around $20-40 \%$ of the cases and is pathognomonic for chronic Chagas' myocarditis. Ventriculography can detect this lesion more frequently than at autopsy.

Focal areas of myocardial atrophy occur at random in the myocardium of the left ventricle. They are seen as zones of akinesia or dyskinesia in ecchograms, or as aneurysmal dilatation in ventriculographies. They can be well demonstrated at autopsy by transillumination of the heart and represent areas of myocardial atrophy. These areas probably result from lesions of the conducting system that may retard the stimulus for contraction. Some non-stimulated focal myocardial areas may then be repeatedly compressed and distended by the rising intraventricular systolic pressure.

Endocardial mural thrombi occurred in $76 \%$ of 208 necropsies, accompanied by infarcts in several organs: lungs (44.2\%), kidneys $(42.0 \%)$, spleen $(19.2 \%)$, brain $(15.0 \%)$. Chagas' heart disease is thus an essentially embolizing condition, at least in its final stages. In some instances thromboemboism may precede the clinical manifestations of congestive cardiac failure. Signs of cerebrovascular disease, thoracic pain with bloody sputum or lumbar pain and hematuria, may appear as the first clinical manifestation of chronic Chagas' heart disease (8). Pulmonary embolism and infarction are ominous events for the patients with Chagas' heart disease. Right ventricular function is usually severely impaired in such patients and sudden disturbances in the lesser circulation may frequently result in death. Infarcts in other organs, such as in the kidney, spleen and central nervous system may show different stages of healing at post-mortem examination. Changes of chronic passive congestion are marked in the liver (nutmeg liver) and relatively mild at the lungs. Chronic diffuse myocarditis with outstanding interstitial fibrosis is microscopically observed. Myocardiocytes are usually hypertrophied, but there are areas of atrophy. This combination of hypertrophic and atrophic myocardial fibers in a background of a chronic active and fibrosing myocarditis is highly suggestive of chagasic etiology. Amastigote forms of $T$. cruzi are rarely found in histological sections. The utilization of immunocytochemical methods allows the recognition of more parasite-positive cases, as well as the application of PCR and DNA probes.

Ultrastructurally, several degrees of regressive changes can be seen in myocardiocytes, as well as basement membrane thickening around them 
and in myocardial capillaries, changes that may interfere with the metabolism and diffusion of nutrients to contractile fibers (10).

\section{Lesions of the conducting system}

Single and combined arrhythmias are frequent. This is consequence of the frequent involvement of the conducting tissue by inflammatory, degenerative and fibrotic changes. Lesions are the same found in the contractile myocardium, but there are some peculiarities as they affect the conduction system. Three of them should be mentioned: 1) in sclero-atrophy the conducting fibers are atrophic, fragmented, or totally absent while the supporting stroma remains, adopting a fibrillar pattern. This is a frequent lesion which may be found affecting the right bundle branch in cases of right bundle branch block or the His main bundle in complete A-V block; 2) fatty infiltration is a curious type of healing for the conducting tissue, since fatty tissue is the least conducting tissue of the organism, due to its low electrolyte content. Sometimes 30 to $70 \%$ of the conducting tissue is replaced by fatty tissue; 3) vascular changes include phlebosclerosis, arterial intimal thickening, ectasia and varicosities seen in the vicinity or within the conducting tissues. Lymphatic vessels may also be dilated. Distribution of the lesions may disclose a specific pattern in relation to the ECG findings. In any case, the A-V node and the posterior fasciculi of the left branch are usually the least involved structures in cases of Chagas' heart disease (3).

Correlations with the ECG findings are generally good, except for the S-A node. In 11 cases examined with continuous serial sections, all presented condensation of the S-A node fibrous stroma, atrophy and fragmentation of the specific fibers, intimal thickening and medial hypertrophy of the main nodal artery and focal mononuclear-cell infiltrations. However, only in a few cases some signs of nodal disfunction were noted in the clinical charts or ECG tracings. Sinus node disfunction presents with transient manifestations and special investigation should be undertaken to detect them. Earlier studies indicated that sick-sinus node syndrome was rare in chronic Chagas' myocarditis (7\%), but when appropriate techniques were applied a much higher incidence $(68 \%)$ was found. These latter figures are more in keeping with the histological studies (6).

\section{DIGESTIVE FORM OF CHRONIC CHAGAS' DISEASE}

Megaesophagus and megacolon found associated with $T$. cruzi infection in some endemic areas of Chagas' disease have no morphological features that would differentiate them from those idiopathic cases sporadically observed anywhere. However, unlike Hirschsprung's disease, disappearance of neurons from the Auerbach plexus is not limited to the distal non-dilated portion 
of the colon in the chagasic megacolon. In megas associated with $T$. cruzi infection focal inflammatory lesions may or may not be present in the muscular coat or along the myo-enteric plexus. When present, they are represented by lymphocytes, macrophages and plasma cells distributed in isolated clusters. Cell destruction and/or proliferation of vascular and connective cells are not present, so infiltration seems rather residual. Within and around the Auerbach plexus there are fibrosis, atrophy of neuronal structures and total or partial absence of neurons. When destruction of neurons is only partial, some sort of serial or stepped sectioning and the application of quantitative or morphometric analysis is absolutely necessary to detect the neuronal loss (16). Intracellular amastigotes are rarely found in the muscular fibers of esophagus or colon. In the early cases hypertrophy of the muscular coat and muscularis mucosae is prominent, but it is replaced by atrophy and dilatation as the disease progresses.

\section{CHAGAS' DISEASE AND HEART TRANSPLANTATION}

Chagasic patients with heart transplants usually have their protozoan infection re-activated during the course of immunosuppressive therapy. Intracellular $T$. cruzi amastigotes may be detected within myocytes when material from endomyocardial biopsy is examined. Mild to moderate myocarditis may also be present. Differential diagnosis between re-activated Chagas' myocarditis and rejection reaction can sometimes be difficult, except when the presence of $T$. cruzi amastigotes is detected. Sometimes fever and subcutaneous nodules are noted. Parasites are then abundant inside macrophages, forming lesions similar to those occasionally seen in very small children with acute Chagas' disease (so-called "lipochagomas"). Collections of amastigote-laden macrophages may also appear in other sites, but curiously enough, parasitemia tends to remain negative. The rapidly multiplying parasites apparently become very sensitive to chemotherapy and usually the infection can be controlled, if not cured, in patients with heart transplants and re-activated $T$. cruzi infection (9).

\section{CHAGAS' DISEASE AND AIDS}

A predominant and sometimes exclusive involvement of the central nervous system has been observed in chagasic patients with AIDS (22). Focal lesions in the brain tends to assume a tumor-like pattern with accumulation of macrophages (microglial cells) loaded with $T$. cruzi amastigotes. Areas of focal necrosis and features of severe meningo-encephalitis may also be present. Parasite-induced changes in other organs, including the heart, are mild or nonexistent. The reason for this peculiar tropism of the parasite to the central nervous system in patients with AIDS, and some other immunodeficiencies, is not yet understood. 


\section{Doença de Chagas: patologia das lesões crônicas}

O trabalho contém uma breve revisão dos aspectos morfológicos da forma indeterminada e da forma crônica cardíaca da doença de Chagas, juntamente com suas correlações clínicas. São particularmente considerados os achados de miocardite focal na forma indeterminada e o envolvimento do miocárdio e do tecido de condução pelas alterações de inflamação e fibrose na forma crônica cardíaca progressiva.

DESCRITORES: Doença de Chagas. Patologia. Forma crônica cardíaca. Forma indeterminada. Miocardite. Fibrose.

\section{REFERENCES}

1. Andrade ZA. The canine model of Chagas' disease. Mem Inst Oswaldo Cruz 79: 77-83, 1984.

2. Andrade ZA, Andrade SG, Correa, R, Sadigursky M, Ferrans, VJ. Myocardial changes in acute Trypanosoma cruzi infection. Ultrastructural evidence of immune damage and the role of microangiopathy. Am J Pathol 144: 1403-1411, 1994.

3. Andrade Z A, Andrade SG. Oliveira G, Alonso DR. Histopathology of the conducting tissue of the heart in Chagas' myocarditis. Am Heart J 93: 316-324, 1978.

4. Andrade ZA, Andrade SG, Sadigursky M. Damage and healing in the conducting tissue of the heart (an experimental study in dogs infected with Trypanosoma cruzi). J Pathol 143: 93-101, 1984.

5. Andrade ZA, Andrade SG, Sadigursky M, Wenthold Jr RJ, Hilbert SL, Ferrans VJ The indeterminate phase of Chagas' disease: ultrastructural characterization of cardiac changes in the canine model. Am J Trop Med Hyg 57: 328-336, 1997.

6. Andrade ZA, Camara EJN, Sadigursky M, Andrade SG. Envolvimento do nodulo sinusal na doença de Chagas. Arq Bras Cardiol, 50: 153-158, 1988.

7. Andrade ZA, Lopes ER, Prata SP. Alterações do sistema de condução do coração em chagásicos acometidos de morte repentina. Arq Bras Cardiol 48: 5-9, 1987.

8. Andrade, ZA. \& Sadigursky, M. Tromboembolismo em chagásicos sem insuficiência cardiaca. Gaz Med Bahia 71: 59-64, 1971.

9. Bocchi EA, Belloti G, Ulip D, Kalil J, Higuchi ML., Fiorelli A, Stolf N, Jatene A Pilegi F. Longterm follow-up after heart transplantation in Chagas' disease. Transplant Proc 25: 1329-1330, 1993.

10. Ferrans. VJ, Milei J, Tomita Y, Storino RA. Basement membrane thickening in cardiac myocytes and capillaries in chronic Chagas' disease. Am. J. Cardiol. 61: 1137-1140, 1988.

11. Higuchi ML, De Morais CF, Pereira Barretto AC, Lopes EA, Stolf N, Bellotti G, Pileggi F. The role of active myocarditis in the development of heart failure in chronic Chagas' disease: a study based on endomyocardial biopsies. Clin Cardiol 10: 665-670, 1987.

12. Kumar S, Tarleton RL. The relative contribution of antibody production and CD8+T cell function to immune control of Trypanosoma cruzi. Parasite Immunol. 20: 207-216, 1998.

13. Lopes ER, Chapadeiro E, Almeida HO, Rocha A. Contribuição ao estudo da anatomia patológica dos corações de chagásicos falecidos subitamente. Rev Soc Bras Med Trop 9: 269-282, 1975.

14. Lopes MF, Veiga VF, Santos AR, Fonseca ME, DosReis GA. Activation-Induced CD4+ T cell death by apoptosis in experimental Chagas' disease. J Immunol 154: 744-752, 1995. 
15. Mady C, Pereira-Barretto AC, lanni BM, Lopes EA, Pileggi F. Right ventricular endomyocardial biopsy in undetermined form of Chagas' disease. Angiology 35: 755-759, 1984.

16. Oliveira JSM. A natural human model of intrinsic heart nervous system denervation: Chagas' cardiopathy. Am Heart J 110: 1092-1098, 1985.

17. Pacheco A, Pinton R, Lemke W. Indeterminate form of Chagas' disease: early ventricular dysfunction unmasked by dobutamine stress ecchocardiography. J Am Coll Cardiol. 24: 132139, 1994.

18. Palacios-Pru E, Carrasco H, Scorza C, Espinoza R. Ultrastructural characteristics of different stages of human chagasic myocarditis. Am J Trop Med Hyg 41: 29-40, 1989.

19. Pimenta J, Miranda M, Pereira CB. Electrophysiologic findings in long-term asymptomatic chagasic individuals. Am Heart J 106: 374-380, 1983.

20. Relatório Oficial da $1^{\text {a }}$ Reunião Anual de Pesquisa Aplicada em Doença de Chagas, Sociedade Brasileira de Medicina Tropical, Araxá, MG, 13-15, dezembro, 1984. Rev Soc Bras Med Trop 18: 46, 1985.

21. Reis DA, Fonseca MEF, Lopes MF. Programmed T-cell death in experimental Chagas' disease. Parasitol. Today 11: 390-394, 1995.

22. Reis DA, Jones EM, Tostes JR S, Lopes ER, Gazzinelli G, Colley DG, McCurley TL Characterization of inflammatory infiltrates in chronic chagasic myocardial lesions: presence of tumor necrosis factor- $\alpha+$ cells and dominance of granzyme A+, CD8+ lymphocytes. Am J Trop Med Hyg 48: 637-644, 1993

23. Rocha A, Meneses ACO, Silva AM, Ferreira MS, Nishioka AS, Burgarelli MKN, Almeida E, Turcato Jr G, Metze K, Lopes ER. Pathology of patients with Chagas' disease and acquired immunodeficiency syndrome. Am J Trop Med Hyg 50: 261-268, 1994.

24. Scalabrini A, Cardoso A, Andrade SG, Andrade ZA-Correlação clínico-patológica na forma indeterminada da doença de Chagas experimental do cão. Arq Bras Cardiol 67: 385-388, 1996.

25. Tarleton RL. Pathology of American Trypanosomiasis. In: Warren KS "Immunology and molecular biology of parasitic diseases", 3rd Edition, Blackwell Scientific Publications, Boston, p. 64-85, 1993.

26. Tostes Jr S, Lopes ER, Pereira FEL, Chapadeiro E Miocardite chagásica crônica humana: estudo quantitativo dos linfócitos CD4+e dos CD8+ no exsudato inflamatório. Rev Soc Bras Med Trop 27: 127-134, 1994. 